\title{
New National Science Foundation Opportunities for Improving Undergraduate Engineering Education
}

\author{
Borrego, M. ${ }^{1}$, Chan Hilton, A. ${ }^{2}$, Everett, L. J. ${ }^{3}$, Finger, S. ${ }^{4}$, Millard, D. ${ }^{5}$, and Yu, Z. ${ }^{6}$ \\ Division of Undergraduate Education \\ National Science Foundation (NSF) \\ Arlington, VA, USA \\ 1'mborrego@nsf.gov; ${ }^{2}$ achanhil@nsf.gov; ${ }^{3}$ leverett@nsf.gov; ${ }^{4}$ sfinger@nsf.gov; ${ }^{5}$ dmillard@nsf.gov; ${ }^{6}$ zyu@nsf.
}

\begin{abstract}
The goal of this mini-workshop is to increase the participants' knowledge of current opportunities at the National Science Foundation (NSF) to support excellence in undergraduate science, technology, engineering, and mathematics (STEM) education. In particular, the discussion focuses on new and current opportunities in the Division of Undergraduate Education as well as highlight examples of project activities that support these opportunities. The miniworkshop uses a highly interactive format, using team-based games and discussion, to engage the participants and to foster the sharing of ideas, to clarify misconceptions, and to potentially initiate new ideas in engineering education innovations and research. This mini-workshop closely encourages the sharing of ideas and interaction amongst peers, and also informs participants about current NSF funding opportunities in STEM education.
\end{abstract}

Keywords-funding opportunities; engineering education; National Science Foundation; student learning; curriculum development; faculty development; institutionalization

\section{GOALS}

The goal of this mini-workshop is to increase the participants' knowledge of current opportunities at the National Science Foundation (NSF) to support excellence in undergraduate science, technology, engineering, and mathematics (STEM) education. In particular, the discussion focuses on new and current opportunities in the Division of Undergraduate Education (DUE) as well as highlight examples of project activities that support these opportunities. The miniworkshop uses a highly interactive format, using team-based games and discussion, to engage the participants and to foster the sharing of ideas, to clarify misconceptions, and to potentially initiate new ideas in engineering education innovations and research. The goal of this mini-workshop closely aligns with the goals of FIE because it encourages the sharing of ideas, interaction amongst peers, and inform participants about current NSF funding opportunities in STEM education.

\section{MINI-WORKSHOP TOPICS}

In this interactive mini-workshop, participants explore new emphases and opportunities for funding high-impact projects in STEM education. Participants actively engage in learning about new and current opportunities, discussing project activities and elements, initiating the design of potential projects and interventions, and identifying fit with available funding programs.

Recently, several NSF funding programs have used and developed creative new mechanisms to greatly advance knowledge building in engineering education, impact educational practice on a broad scale, and significantly increase the number and quality of graduating engineers. For example, the program Widening Implementation and Demonstration of Evidence-Based Reforms (WIDER) was announced in April 2013. The goal of the WIDER program is to scale up the application of highly effective methods of STEM teaching and learning within and across the higher education sector to achieve improved student learning, increased numbers of students choosing STEM major, and improved retention to graduation of all STEM majors.

A new program called Catalyzing Advances in Undergraduate STEM Education (CAUSE) has been proposed that, among other goals, is anticipated to include the goals of past DUE programs (Transforming Undergraduate Education in STEM (TUES), WIDER, and STEM Talent Expansion Program (STEP)). Additional undergraduate STEM education programs are highlighted to allow participants to identify potential programs that might match their ideas and goals. Moreover, participants will become familiar with NSF and its goals to put these opportunities into context. Participants also will become aware of the recent revisions in the NSF Proposal \& Award Policies \& Procedures Guide (PAPPG), which affect proposal preparation, merit review, and reporting.

\section{QUALIFICATIONS OF PRESENTERS}

All the presenters in this mini-workshop are program directors in the Division of Undergraduate Education at the National Science Foundation. Each presenter has extensive experience in leading and engaging in engineering education and research projects as well as engaging with students in and out of the classroom. The presenters work very closely in developing the STEM education funding programs at NSF. In particular, they are directly involved in writing the program solicitations, reviewing proposals, making funding decisions, 
communicating expectations to principal investigators, and interacting with potential principal investigators.

\section{WORKSHOP AGENDA}

The mini-workshop includes the following topics:

- Introduction and overview of mini-workshop and format

- NSF organization structure and its goals

- Interactive activity on NSF opportunities to improve undergraduate STEM education, using a team-based game and follow-up discussion to highlight key elements of each program

- Summary of STEM undergraduate education opportunities at NSF and follow-up questions and discussion, lead by presenters

- Interactive discussion on project activities

- This focuses on the types of activities within a potential project and key elements of a successful project.

o Participants have opportunities to think about and discuss their project ideas

- $\quad$ Revised NSF Proposal \& Award Policies \& Procedures Guide (PAPPG)

○ Highlights on changes in proposal preparation and reporting

- Clarification in the merit review criteria

○ Questions and discussion

\section{INTENDED AUDIENCE}

The anticipated audience of this mini-workshop includes STEM educators who are interested in developing high-impact projects in STEM undergraduate education. This includes instructors, faculty members, and administrators at U.S. college and universities in the engineering, computing, and engineering education disciplines. The content of this mini-workshop would be of interest to the broad FIE audience.

\section{KNOWLEDGE ATtendeEs Will ACQUiRE}

At the end of the mini-workshop, participants will have extended their knowledge about opportunities at NSF for undergraduate STEM education. In particular, the participants should be able to:

- Describe the goals, objectives, and scopes of the programs discussed;

- Identify the program(s) that fit their needs and interests;

- Discuss high-impact project activities that support the goals of the opportunities; and

- Summarize revisions to the proposal preparation guidelines, review process, and project reporting requirements.

Through the highly interactive and engaging activities, participants will have opportunities to increase their knowledge about NSF programs in STEM education, initiate new ideas in engineering education innovations and research, clarify questions and misconceptions related to the opportunities discussed, and share ideas. 